\title{
Correction to: The assessment of the ASGE-grading system of ERCP: a large-sample retrospective study
}

\author{
Feng Zhou ${ }^{1} \cdot$ Xiaoyun Zhan ${ }^{1} \cdot$ Conghua Song ${ }^{1} \cdot$ Guohua $\mathrm{Li}^{1} \cdot$ Junbo Hong ${ }^{1} \cdot$ Youxiang Chen $^{1} \cdot$ Xiaojiang Zhou $^{1}$ (1)
}

Published online: 19 January 2022

(c) The Author(s), under exclusive licence to Springer Science+Business Media, LLC, part of Springer Nature 2022

\section{Correction to: Surgical Endoscopy}

https://doi.org/10.1007/s00464-021-09000-0

This article was updated to correct an error in the Methods section of the Abstract: "from January 2010 to December 2019" was corrected to read "from January 2011 to December 2020."

Publisher's Note Springer Nature remains neutral with regard to jurisdictional claims in published maps and institutional affiliations.

The original article can be found online at https://doi.org/10.1007/ s00464-021-09000-0.

Xiaojiang Zhou

yfyzxj1970@163.com

1 Department of Gastroenterology, First Affiliated Hospital of Nanchang University, No. 17 Yongwaizheng Street, Nanchang 330000, Jiangxi Province, China 